\title{
ANÁlISE DO SOLO, DA ÁGUA E DE PRODUTOS DO COTIDIANO COMO FERRAMENTA PARA O ENSINO DE ÁCIDOS E BASES
}

Soil, water and daily products analysis as a tool for acid and base teaching Análisis de suelos, agua y productos diarios como herramienta para la enseñanza de ácidos y bases

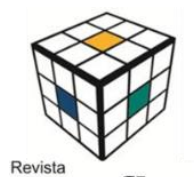

Desafios

Artigo Original Original Article Artículo Original

\section{Elias Ferreira de Castro $^{l}$; Klenicy Kazumy de Lima Yamaguchi ${ }^{2 *}$ \\ ${ }^{1}$ Graduado em licenciatura em Ciências: Biologia e Química, Instituto de Saúde e Biotecnologia-UFAM, Estrada Coari-Mamiá, Espírito Santo, 69460-000, Coari, Amazonas, Brasil. \\ ${ }^{* 2}$ Professora Adjunta do Instituto de Saúde e Biotecnologia - UFAM, Estrada Coari-Mamiá, Espírito Santo, 69460-000, Coari, Amazonas, Brasil, e-mail: klenicy@gmail.com}

Artigo recebido em 26/12/2019 aprovado em 04/02/2020 publicado em 24/03/2020.

\section{RESUMO}

A química está presente no dia-a-dia e utilizar materiais conhecidos pelos discentes torna-se uma ferramenta importante para facilitar o processo de aprendizagem significativa dos discentes. O objetivo desta pesquisa foi realizar a análise o $\mathrm{pH}$ do solo, da água de um igarapé e de materiais comuns do cotidiano doméstico como atividade experimental do conteúdo de ácido-base para discentes do terceiro ano do ensino Médio de uma escola pública no município de Coari, Amazonas, Brasil. Para tanto, utilizou-se indicador natural de repolho roxo e indicador de papel, classificando os materiais em ácido, base e neutros. A atividade realizada teve a participação e interesse dos discentes, sendo uma alternativa simples e de baixo custo para explicar o conteúdo de ácido-base nas aulas de química, tornando o aprendizado mais significativo.

Palavras-chave: ácido-base, Coari, ensino de Química.

\section{ABSTRACT}

Chemistry subject is present daily and awareness throughout discourses becomes important to facilitate the meaningful learning process of learners. The aim of this research is $\mathrm{pH}$ analysis of solo, water-of-igarape and common daily materials as an experimental activity of the acid-base content for the students of the third year of high school in a public school in Coari, Amazonas, Brazil. For this, a natural indicator of purple cabbage and paper indicator is used, classifying the materials in acid, base and neutral. The class had a participation and interest of the students, being a simple and low cost alternative to explain the basic content in the classes of chemistry, making the learning more significant.

Keywords: acid-base, Coari, teaching Chemistry

\section{RESUMEN}

La química está presente en la vida cotidiana y el uso de materiales conocidos por los estudiantes se convierte en una herramienta importante para facilitar el proceso de aprendizaje significativo de los estudiantes. El objetivo de esta investigación fue analizar el pH del suelo, el agua de un arroyo y los materiales comunes de la vida cotidiana como actividad experimental de contenido ácido-base para estudiantes del tercer año de secundaria de una escuela pública en Coari. , Amazonas, Brasil. Para esto, utilizamos el indicador natural de repollo rojo y el indicador de papel, clasificando los materiales en ácido, base y neutro. Esta actividad contó con la participación e interés de los estudiantes, siendo una alternativa simple y de bajo costo para explicar el contenido ácido-base en las clases de química, haciendo que el aprendizaje sea más significativo.

Descriptores: base ácida, Coari, enseñanza de la química 


\section{INTRODUÇÃO}

A maioria das cidades na região Amazônica nasceu às margens de rio. Com o tempo, elas cresceram e com o aumento da população e do desenvolvimento da industrialização foi gerado uma necessidade cada vez maior de água. Estudar assuntos que são do cotidiano dos discentes favorece o ensino por meio da aplicação de conceitos teóricos no dia-a-dia dos discentes.

Entre as disciplinas estudadas, tem-se a química como uma ciência que se preocupa em entender o mundo no seu sentido material, refletindo na constituição e transformação da matéria (Oliveira, et al. 2009). A importância do ensino de Química não se encontra exclusivamente na apropriação de um conhecimento científico, mas no processo de aprendizado dos indivíduos dando a oportunidade dos mesmos interagirem com a sociedade, proporcionando uma facilidade maior de interpretação e interação (Chassot, 1990).

Os conhecimentos químicos ainda nos tempos atuais são considerados um obstáculo para os discentes que os veem de maneira totalmente desvinculados da sua realidade. O produto desta aprendizagem por memorização tem como consequência, um esquecimento rápido do conhecimento aprendido, fazendo com que, os alunos não percebam as contribuições de determinado conteúdo propicia em seu cotidiano, ocasionando incompreensão dos conteúdos e desinteresse pela disciplina (Schnetzler,1992).

Segundo Ausubel (2003), a aprendizagem significativa ocorre por meio da interação entre conhecimentos prévios e conhecimentos novos, utilizando uma interação não-literal e não-arbitrária. Nesse processo, os novos conhecimentos adquirem significado para o sujeito e os conhecimentos prévios adquirem novos significados ou maior estabilidade cognitiva. Dessa forma, o ensino de química aplicado, seja por meio de atividades lúdicas ou experimentais, proporciona aos discentes a aplicação dos conceitos teóricos.

Pesquisas na literatura demonstram que atividades experimentais apresentam dificuldade em serem executadas devido à falta de estrutura na escola e a escassez de recursos para obtenção de reagentes (Yamaguchi e Nunes, 2019; Uchôa et al., 2016). Segundo Alves e Silva (2012), o professor apresenta um papel muito importante nesse quadro, sendo um agente de transformação ao aplicar suas práticas pedagógicas para o dia-a-dia dos alunos, a fim para deixar as aulas mais atrativas e proveitosas. Como consequência, os conteúdos acabam não sendo relacionados com o que é aprendido em sala de aula. Faz-se necessário demonstrar aos alunos que o conteúdo aprendido na teoria faz parte do meio social promovendo uma série de habilidades e competências que auxiliam no processo de ensino e aprendizagem (Oliveira, 2010). Como proposta, tem-se a utilização de materiais alternativos e de uso doméstico como ferramenta para as aulas experimentais. Dessa forma, a missão do professor discutindo e demostrando teorias e práticas do assunto, é alcançado ao ser mediador no processo de aprendizagem significativa dos discentes.

O presente trabalho tem como objetivo apresentar uma prática do ensino de química com metodologia adaptada para o cotidiano dos alunos, utilizando materiais alternativos para discutir a aplicação dos conceitos de ácido e base. Entre os materiais, cita-se o solo da escola e a água do principal igarapé da cidade visando contextualizar o assunto teórico.

A demonstração de processos físicos, químicos e bioquímicos em atividades presentes no cotidiano 
permite ao aluno a percepção tanto dos processos químicos quanto da construção de um conhecimento científico, fazendo com que exista uma relação com as inovações tecnológicas e suas aplicações ambientais, sociais, políticas e econômicas (BRASIL, 2002).

\section{MATERIAIS E MÉTODOS}

A pesquisa foi realizada em uma escola pública no município de Coari, Amazonas, Brasil. Participaram das atividades 25 alunos, cursando o $3^{\circ}$ ano do ensino médio, turno noturno. Os procedimentos foram desenvolvidos em 4 etapas.

Etapa 1: Aplicação do questionário Inicial que avaliou o conhecimento prévio dos alunos.

Etapa 2: Aula expositiva com duas aulas teóricas com o auxílio de data show e quadro branco. Houve a regência do assunto "ácido e base", sua importância e aplicações e o uso de indicadores e as metodologias de identificação das classes: ácido, base e neutro.

\section{Etapa 3: Experimentação}

Houve pesquisa em campo, onde os discentes puderam realizar a coleta do solo e da água do igarapé, próximos a instituição. Os materiais coletados foram reservados e organizados para realização das práticas de química. Realizou-se a atividade experimental em outras duas aulas práticas. Inicialmente separou-se os materiais do cotidiano: detergente, óleo, água sanitária, refrigerante, magnésio, café, sabão em pó, sal, açúcar, limão, creme dental, bicarbonato e leite; Em seguida, os discentes fizeram soluções dos materiais que haviam sido coletados anteriormente: água e solo do igarapé. O preparo da solução com o solo seguiu a metodologia descrita por Antunes et al. (2009) utilizando uma proporção de $10 \mathrm{~g}$ de solo para $25 \mathrm{~mL}$ de água destilada.

$\mathrm{Na}$ análise das classes (ácido, base e neutra), foram utilizados dois procedimentos: uso de indicador natural utilizando repolho roxo em uma solução hidroalcoolica (1:1) e uso de papel indicador tornassol.

Etapa 4: Houve uma explicação sobre o uso de indicadores e os resultados obtidos na culminância. Em seguida aplicou-se o questionário final, utilizado como parâmetro para analisar o grau de compreensão dos alunos durante as aulas aplicadas.

Ao final de todo o processo de aplicação do projeto foi realizado a tabulação dos dados coletados durante as aulas.

\section{RESULTADOS E DISCUSSÃO}

No início do período letivo haviam 40 alunos matriculados, 30 estavam frequentando as aulas, no entanto somente 25 participaram da atividade, verificando uma alta evasão dos discentes.

As atividades de intervenção tiveram como finalidade transmitir aos alunos o conteúdo de ácido e base de uma maneira mais prática e com maior profundidade teórica para que pudesse ser aplicado no cotidiano de uma maneira somatória. Com a aplicação do questionário inicial percebeu-se dificuldades dos discentes com relação ao assunto avaliado.

Embora os discentes estivessem no terceiro ano e teoricamente já tivessem contato com o referido assunto no segundo ano do ensino médio e no nono ano do ensino fundamental, $8 \%$ afirmaram não saber o que seriam substâncias ácidas (questão 1), 16\% não sabiam o que era substâncias básicas (questão 12), 40\% não sabiam o que era pH e 60\% afirmaram não conhecer 
ou lembrar do assunto (questão 11). Os resultados completos podem ser visualizados no quadro 1 .

Os alunos associaram o ácido a uma característica do mesmo, o paladar azedo. Esse dado foi verificado nas perguntas 4, 7 e 12 do questionário. Em relação a base, os mesmos tinham dificuldade em distinguir base ou qualquer outra característica desse grupo, como pode ser percebida nas perguntas 5, 6, 9, $11 \mathrm{e} 12 \mathrm{e}$ em relação à neutralidade o conhecimento era ainda menor o que fica bem claro na pergunta 10 .

Em relação a disciplina de química, muitos alunos afirmaram durante a atividade, que apresentavam pouca ou nenhuma afinidade com a matéria, o que pode refletir diretamente nas respostas das questões, tornando mais difícil a transmissão dos conhecimentos devido a barreira o que os mesmos têm naturalmente. Verificou-se que na turma havia uma quantidade considerável de discentes que trabalhavam durante o dia e que notoriamente estavam cansados. Esse é um problema detectado frequentemente no Ensino regular noturno e na modalidade de Educação de Jovens e Adultos (EJA), onde os autores reportam que são comumente formados por adultos, que trabalham e sustentam família
Quadro 1: Questionário inicial

\begin{tabular}{|c|c|c|c|}
\hline Questões & Alternativas & $\begin{array}{l}\text { Resultados } \\
\text { (N) }\end{array}$ & $\begin{array}{l}\text { Resultados } \\
(\%)\end{array}$ \\
\hline $\begin{array}{l}1^{\circ} \text { Você sabe o que são } \\
\text { substâncias ácidas? }\end{array}$ & $\begin{array}{l}\text { Sim } \\
\text { Não }\end{array}$ & $\begin{array}{l}23 \\
02\end{array}$ & $\begin{array}{l}92 \% \\
08 \%\end{array}$ \\
\hline $\begin{array}{l}2^{\circ} \text { você sabe o que } \\
\text { são substâncias } \\
\text { básicas? }\end{array}$ & $\begin{array}{l}\text { Sim } \\
\text { Não }\end{array}$ & $\begin{array}{l}21 \\
04\end{array}$ & $\begin{array}{l}84 \% \\
16 \%\end{array}$ \\
\hline $\begin{array}{l}3^{\circ} \text { você sabe o que é } \\
\text { pH? }\end{array}$ & $\begin{array}{l}\text { Sim } \\
\text { Não }\end{array}$ & $\begin{array}{l}15 \\
10\end{array}$ & $\begin{array}{l}60 \% \\
40 \%\end{array}$ \\
\hline $\begin{array}{l}4^{\circ} \text { Cite dois } \\
\text { produtos ácidos que } \\
\text { você usa no dia-a- } \\
\text { dia? }\end{array}$ & $\begin{array}{l}\text { Limão } \\
\text { Camu-camu } \\
\text { Vinagre } \\
\text { Refrigerante } \\
\text { Manga } \\
\text { Cacau } \\
\text { Óleo } \\
\text { Laranja } \\
\text { Cebola } \\
\text { Farinha } \\
\text { Erro }\end{array}$ & $\begin{array}{l}1 \\
7 \\
4 \\
2 \\
1 \\
2 \\
5 \\
2 \\
3 \\
10 \\
1\end{array}$ & $\begin{array}{l}44 \% \\
02 \% \\
14 \% \\
08 \% \\
04 \% \\
02 \% \\
04 \% \\
10 \% \\
04 \% \\
06 \% \\
02 \%\end{array}$ \\
\hline $\begin{array}{l}5^{\circ} \text { Cite dois } \\
\text { produtos básicos } \\
\text { que você utiliza no } \\
\text { seu cotidiano. }\end{array}$ & $\begin{array}{l}\text { Detergente } \\
\text { Leite } \\
\text { Sabão } \\
\text { Sabonete } \\
\text { Creme dental } \\
\text { Agua sanitária } \\
\text { Erro }\end{array}$ & $\begin{array}{l}8 \\
15 \\
12 \\
1 \\
1 \\
4 \\
9\end{array}$ & $\begin{array}{l}16 \% \\
30 \% \\
24 \% \\
02 \% \\
02 \% \\
08 \% \\
18 \%\end{array}$ \\
\hline $\begin{array}{l}6 \text { Assinale a } \\
\text { alternativa que } \\
\text { representa dois } \\
\text { produtos caseiros } \\
\text { com propriedades } \\
\text { básicas }\end{array}$ & $\begin{array}{ll}\begin{array}{l}\text { Detergente } \\
\text { vinagre }\end{array} & \mathrm{e} \\
\text { Bicarbonato } & \mathrm{e} \\
\text { açúcar } & \\
\text { Sal e leite } & \\
\text { Coca-cola } & \mathrm{e} \\
\text { água de cal } & \\
\text { Leite } & \\
\text { magnésia } & \mathrm{e} \\
\text { sabão } & \end{array}$ & $\begin{array}{l}2 \\
5 \\
4 \\
2 \\
12\end{array}$ & \begin{tabular}{r|}
$08 \%$ \\
$20 \%$ \\
$16 \%$ \\
$08 \%$ \\
$48 \%$ \\
\end{tabular} \\
\hline $\begin{array}{l}7^{\circ} \text { Assinale as } \\
\text { alternativas que } \\
\text { representam dois } \\
\text { produtos caseiros } \\
\text { com propriedade } \\
\text { acida. }\end{array}$ & 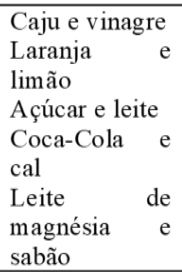 & $\begin{array}{l}2 \\
20 \\
2 \\
1 \\
0\end{array}$ & \begin{tabular}{l|}
$08 \%$ \\
$80 \%$ \\
$08 \%$ \\
$04 \%$ \\
$00 \%$
\end{tabular} \\
\hline $\begin{array}{l}8^{\circ} \text { Em sua opinião } \\
\text { qual } \\
\text { produtos é mais } \\
\text { ácido. }\end{array}$ & $\begin{array}{l}\text { Suco de maçã } \\
\text { Detergente } \\
\text { Saliva humanā } \\
\text { Suco gástrico } \\
\text { Café negro }\end{array}$ & $\begin{array}{l}2 \\
5 \\
9 \\
4 \\
5\end{array}$ & $\begin{array}{l}08 \% \\
20 \% \\
36 \% \\
16 \% \\
20 \%\end{array}$ \\
\hline
\end{tabular}

Cativar a atenção para o aprendizado significativo é um desafio para os docentes. Para tanto, procurou-se apresentar o conteúdo "ácido e base" utilizando metodologia ativa, onde os discentes puderam expor os conhecimentos prévios. Verifica-se que no ensino de Química quando ministrado de forma 
isolada e não contextualizada pode desestimular ou fazer os alunos desacreditaram na escola como processo de evolução pessoal.

Assim, os pesquisadores procuraram valorizar a participação dos discentes incentivando-os a exporem suas ideias e seus questionamentos, apresentando os conhecimentos informais adquiridos por suas experiências pessoais.

A aula expositiva foi realizada com sucesso, onde houve uma intensa participação dos alunos através de perguntas, curiosidades e mesmo opiniões próprias como exemplos e situações que ocorriam no cotidiano em relação ao assunto pH (figura 1).

Figura 1: aula expositiva

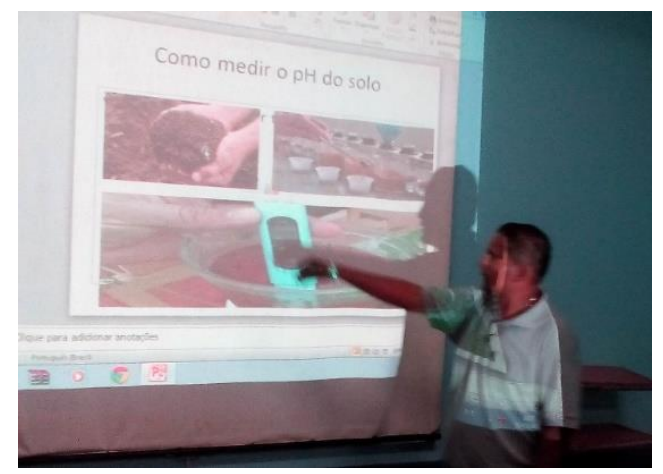

Com uma metodologia clara e didática foi demostrado a aplicação das metodologias de identificação das classes: ácido, base e neutro. Foi apresentado os tipos de indicadores: papel, naturais e um pHmetro. Por meio das imagens e contextualização, os discentes tiveram melhor capacidade de absorção, tornando as aulas participativas.

Para iniciar as aulas experimentas foram coletados solo e água do igarapé do Pera e da escola. Foram preparados os produtos utilizados no cotidiano e o indicador do suco do repolho roxo. Todos esses materiais foram preparados pelos discentes, orientados pelo professor.
A aula prática deu-se início com a explicação de como seria feito os procedimentos do experimento. Houve uma participação intensa dos alunos nas aulas práticas procurando fazer mais corretamente possível os experimentos através de perguntas e participação. Dando continuidade apresentou-se os materiais que seriam utilizados. Na primeira etapa utilizou-se a fita de tornassol para medir o $\mathrm{pH}$ dos materiais e na segunda etapa utilizou-se o indicador do suco do repolho roxo. Todos os resultados foram anotados pelos os discentes.

Em relação ao experimento, a coloração adquirida pelos materiais após a adição do indicador do suco do repolho roxo chamou a atenção dos discentes devido as colorações resultantes da reação química (figura 2). Tal observação foi condizente com o trabalho de Cortes et al., (2007), que afirmam que o uso de corantes naturais em atividades experimentais, tanto no ensino médio quanto no ensino superior atrai o interesse dos estudantes para o conteúdo abordado, devido à coloração das espécies químicas contidas nos tecidos vegetais e suas mudanças de cor em função do pH. Além disso, os autores destacam que o uso de materiais alternativos ligam a química com o cotidiano dos estudantes.

Figura 2: Experimento ácido e base. A) Indicadores, B) materiais utilizados e C) amostras 


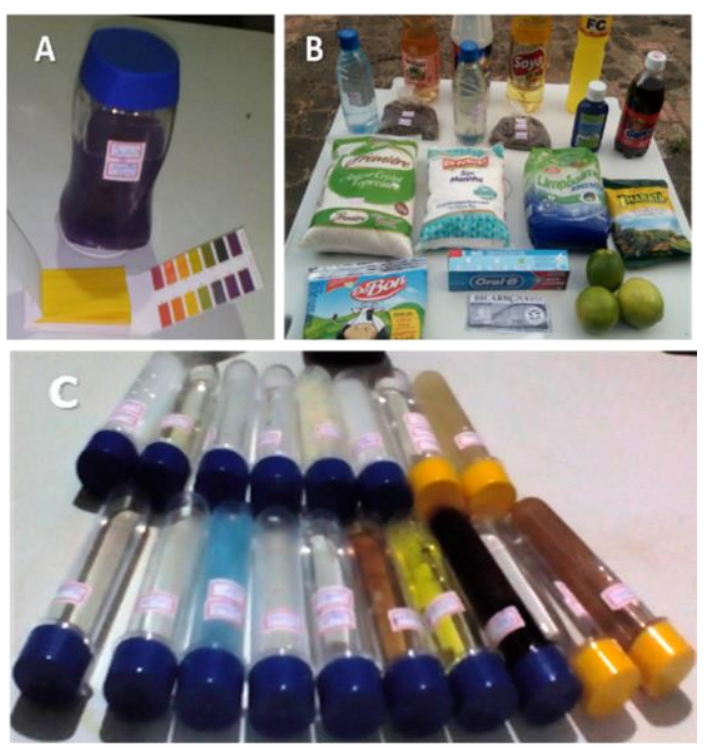

$\mathrm{Na}$ análise da água do igarapé obteve-se o resultado com pH 6 e o solo pH 5, ambos ácidos. Foi observado e discutido pelos alunos e pelo professor os diferentes resultados, onde o interesse foi estimulado pela curiosidade e vontade de ter resultados condizentes com os trabalhos reportados na literatura.

Segundo Lopes et al., (1991), os solos podem ser naturalmente ácidos devido a processos de remoção de elementos básicos como $\mathrm{K}, \mathrm{Ca}, \mathrm{Mg}, \mathrm{Na}$ ou em função da própria pobreza em bases do

material de origem. A consequência dessa alcalinidade relaciona-se com a diminuição de microrganismos presentes, e a dificuldade de crescimento de alguns vegetais como a soja, o feijão e o trigo. Tal afirmação foi constatada nessa pesquisa, onde a área em que foi retirada a amostra para o experimento apresentava pouca vegetação e árvores frutíferas.

Através desse processo percebeu-se que a aula prática tem muito a acrescentar no aprendizado do aluno tornando-a produtiva e com maior absorção dos conteúdos, permitindo o contato direto com os materiais estudado na teoria e aplicado na prática.

Com aplicação de um questionário final foi exigido um conhecimento mais aprofundado dos alunos. A taxa de acerto foi satisfatória, o que ficou bem claro nas 20 questões aplicadas (quadro 2). Apenas nas questões 6, 11 e 13 tivemos menos de 50\% de acertos. Levando em consideração o grau de dificuldade em relação ao primeiro questionário, o resultado obtido pode ser percebido na evolução no conhecimento dos alunos.

Quadro 2: Questionário final 


\begin{tabular}{|c|c|c|}
\hline $1^{\circ} \mathrm{O}$ que você entende sobre ácido. & $\begin{array}{l}\text { Substância azeda. } \\
\text { Vinagre. } \\
\text { Limão. } \\
\text { Material de limpeza. } \\
\text { É azedo. } \\
\text { Quando menor o número na escala mais } \\
\text { ácido é. }\end{array}$ & $\begin{array}{l}75 \% \\
5 \% \\
5 \% \\
5 \% \\
5 \% \\
5 \%\end{array}$ \\
\hline $2^{\circ} \mathrm{O}$ que você entende sobre base. & $\begin{array}{l}\text { Substância adstringente } \\
\text { Não tem gosto. } \\
\text { Não é azedo. } \\
\text { Material de limpeza. } \\
\text { Quando menor o número na escala de } \\
\text { pH. } \\
\text { Não responderam. }\end{array}$ & $\begin{array}{l}25 \% \\
25 \% \\
10 \% \\
5 \% \\
5 \% \\
25 \% \\
5 \%\end{array}$ \\
\hline $3^{\circ}$ Qual função da escala de $\mathrm{pH}$ ? & $\begin{array}{l}\text { Analisa a corrente da água } \\
\text { Analisar a turbidez da água } \\
\text { A analisar valores que servem para } \\
\text { determinar o grau de acidez ou de } \\
\text { basicidade de uma dada substância. } \\
\text { Várias entre } 0 \text { a } 14 \text {, sendo o valor médio, } \\
\text { o sete correspondente a solução neutras . } \\
\text { Analisar erros que podem ocorrer nas } \\
\text { medidas do pH ocasionadas por diversos } \\
\text { fatores, entre eles. }\end{array}$ & $\begin{array}{l}5 \% \\
0 \% \\
90 \% \\
0 \%\end{array}$ \\
\hline & & $5 \%$ \\
\hline $\begin{array}{l}4^{\circ} \mathrm{O} \text { hidróxido de sódio e conhecido } \\
\text { também como: }\end{array}$ & $\begin{array}{l}\text { Muriático } \\
\text { Soda cáustica } \\
\text { Hidróxido de sódio } \\
\text { Cal }\end{array}$ & $\begin{array}{l}00 \% \\
5 \% \\
70 \% \\
25 \%\end{array}$ \\
\hline $5^{\circ}$ Cloreto de sódio e conhecido como & $\begin{array}{l}\text { Cal } \\
\text { Leite de magnésia } \\
\text { Sal de cozinha } \\
\text { Muriático }\end{array}$ & $\begin{array}{l}5 \% \\
25 \% \\
60 \% \\
10 \%\end{array}$ \\
\hline $6^{\circ}$ A soda cáustica é usada para. & $\begin{array}{l}\text { É usada na fabricação de sabão } \\
\text { É usada para temperar salada } \\
\text { É obtida dos minerais } \\
\text { É obtida das salinas }\end{array}$ & $\begin{array}{l}40 \% \\
00 \% \\
5 \% \\
55 \%\end{array}$ \\
\hline $7^{\circ} \mathrm{O}$ ácido cítrico aparece no: & $\begin{array}{l}\text { Limão } \\
\text { Sabão } \\
\text { Vinagre } \\
\text { Leite } \\
\end{array}$ & $\begin{array}{l}75 \% \\
0 \% \\
25 \% \\
0 \%\end{array}$ \\
\hline $\begin{array}{l}\quad 8^{\circ} \text { Sabor azedo e boa condutividade } \\
\text { elétrica em solução aquosa são características } \\
\text { de: }\end{array}$ & $\begin{array}{l}\text { Bases } \\
\text { Óxidos } \\
\text { Ácidos } \\
\text { Sais }\end{array}$ & $\begin{array}{l}10 \% \\
5 \% \\
85 \% \\
0 \%\end{array}$ \\
\hline $\begin{array}{l}9^{\circ} \mathrm{O} \text { sabor das bases, que lembra frutas } \\
\text { verdes, é: }\end{array}$ & $\begin{array}{l}\text { Salgado } \\
\text { Azedo } \\
\text { Amargo } \\
\text { Adstringente }\end{array}$ & $\begin{array}{l}0 \% \\
20 \% \\
10 \% \\
70 \%\end{array}$ \\
\hline $\begin{array}{c}10^{\circ} \quad \text { Composto que, quando } \\
\text { dissociado, produz cátion } \mathrm{H}+\text {. }\end{array}$ & $\begin{array}{l}\text { Base } \\
\text { Acido } \\
\text { Oxido } \\
\text { Sal }\end{array}$ & $\begin{array}{l}0 \% \\
75 \% \\
00 \% \\
25 \%\end{array}$ \\
\hline
\end{tabular}




\begin{tabular}{|c|c|c|}
\hline $\begin{array}{l}11^{\circ} \text { compostos alcalinos de sabor } \\
\text { adstringente, e o mesmo que base: }\end{array}$ & $\begin{array}{l}\text { Hidróxido } \\
\text { Ácidos } \\
\text { Sal } \\
\text { Oxido }\end{array}$ & $\begin{array}{l}25 \% \\
15 \% \\
45 \% \\
15 \%\end{array}$ \\
\hline $\begin{array}{l}12^{\circ} \text { Os ácidos e bases apresentam as } \\
\text { seguintes características. } \\
\text { Marque (A) para ácido e (B) para } \\
\text { bases. }\end{array}$ & $\begin{array}{l}\text { Reagem com os ácidos, produzindo sal e } \\
\text { água. } \\
\text { Tem sabor azedo. } \\
\text { Reagem com hidróxidos, produzindo sal } \\
\text { e agua } \\
\text { Conduzem bem a eletricidade, quando } \\
\text { em solução. } \\
\text { Tem sabor adstringente } \\
\text { Alteram a cor dos indicadores. } \\
\text { Que conduzem bem a eletricidade, } \\
\text { quando em solução. }\end{array}$ & $\begin{array}{l}65 \% \\
80 \% \\
60 \% \\
80 \% \\
80 \% \\
75 \% \\
30 \%\end{array}$ \\
\hline $\begin{array}{l}13^{\circ} \text { Marque os produtos com o } \mathrm{pH} \\
\text { neutro. }\end{array}$ & $\begin{array}{l}\text { Agua sanitária } \\
\text { Condicionador } \\
\text { Leite } \\
\text { Sal } \\
\text { Açúcar } \\
\text { Sabonete } \\
\text { Detergente nêutron } \\
\text { Agua de torneira } \\
\text { Sabão em pó } \\
\text { Shampoo }\end{array}$ & $\begin{array}{l}15 \% \\
7.5 \% \\
10 \% \\
7.5 \% \\
10 \% \\
10.8 \% \\
15 \% \\
10 \% \\
6.7 \% \\
7.5 \%\end{array}$ \\
\hline $\begin{array}{l}14^{\circ} \text { Como e o nome do equipamento a } \\
\text { que verificar o } \mathrm{pH} \text {. }\end{array}$ & $\begin{array}{l}\text { pHmetro } \\
\text { Espectrofotômetro } \\
\text { Balança } \\
\text { Becker }\end{array}$ & $\begin{array}{l}100 \% \\
00 \% \\
00 \% \\
00 \%\end{array}$ \\
\hline $\begin{array}{l}15^{\circ} \text { Exemplifique um produto neutro } \\
\text { que você utiliza no dia - dia. }\end{array}$ & $\begin{array}{l}\text { Detergente nêutron } \\
\text { Agua de torneira } \\
\text { Limão } \\
\text { Açúcar } \\
\text { Sal } \\
\text { Soro }\end{array}$ & $\begin{array}{l}15 \% \\
15 \% \\
35 \% \\
5 \% \\
25 \% \\
5 \%\end{array}$ \\
\hline $\begin{array}{l}16^{\circ} \text { Exemplifique um produto base } \\
\text { que você utilizar no dia a - dia. }\end{array}$ & $\begin{array}{l}\text { leite } \\
\text { Agua sanitária } \\
\text { Creme dental } \\
\text { Sabão em po } \\
\text { Sabão } \\
\text { Erros }\end{array}$ & $\begin{array}{l}20 \% \\
5 \% \\
10 \% \\
10 \% \\
5 \% \\
50 \%\end{array}$ \\
\hline $\begin{array}{l}17^{\circ} \text { Exemplifique um produto nêutron } \\
\text { que você utilizar no dia a dia. }\end{array}$ & $\begin{array}{l}\text { Limão } \\
\text { Caju } \\
\text { Refrigerante } \\
\text { Vinagre } \\
\text { Óleo }\end{array}$ & $\begin{array}{l}65 \% \\
10 \% \\
10 \% \\
10 \% \\
5 \%\end{array}$ \\
\hline $\begin{array}{l}18^{\circ} \text { Qual a sua opinião em relação a } \\
\text { atividade de interversão realizada ? }\end{array}$ & $\begin{array}{l}\text { Ótimo } \\
\text { Boa } \\
\text { Media } \\
\text { Fraco }\end{array}$ & $\begin{array}{l}80 \% \\
20 \% \\
00 \% \\
00 \%\end{array}$ \\
\hline $19^{\circ}$ Você gosta de atividade pratica? & $\begin{array}{l}\text { Sim } \\
\text { Não }\end{array}$ & $\begin{array}{l}95 \% \\
5 \%\end{array}$ \\
\hline
\end{tabular}


$20^{\circ}$ Complete a escala de $\mathrm{pH}$ com suas medidas e quais são?

\begin{tabular}{|l|l}
\hline Ácido & $90 \%$ \\
Base & $90 \%$ \\
Nêutron & $85 \%$ \\
Acido Crescente & $70 \%$ \\
Base Crescente & $45 \%$ \\
\hline
\end{tabular}

No trabalho reportado por Antunes e colaboradores (2009), utilizando a determinação de pH do solo para o ensino de ácido-base, a percentagem de acerto das cinco questões analisadas variou de 14 à $86 \%$. O resultado de acerto das autoras citadas é condizente com os resultados desta pesquisa. Muito além dos acertos, é necessário que o pesquisador possa ter um olhar mais abrangente para os resultados das atividades realizadas, analisando aspectos qualitativos como o interesse, participação e entusiasmo dos discentes. Os valores implícitos da aprendizagem por meio da organização de trabalhos em equipe, a organização, a observação crítica dos fenômenos e a relação interdisciplinar fazem com que o conhecimento possa ser mais abrangente.

O estudo de materiais comumente utilizados pelos discentes como o solo e a água fizeram com que houvesse correlações necessárias para aprimorar os conteúdos teóricos anteriormente descritos pelos discentes. A realização da atividade prática trouxe à tona o interesse investigativo do aluno sobre o assunto em debate e o discente pôde tornar-se o agente ativo do aprendizado.

A percepção das características da água trouxe consequências que estavam além do conteúdo da atividade experimental, como a abordagem sobre o uso racional do recurso hídrico, a influência da poluição, assoreamento e de mananciais, rios, lagos e lençóis freáticos, deterioração de ambiente e a extinção de diferente formas de vida, sendo um tema amplo para aplicação interdisciplinar.

\section{CONCLUSÃO}

A atividade realizada atingiu os objetivos propostos proporcionando motivação aos discentes e execução de um procedimento de ensino para determinar o $\mathrm{pH}$ do solo, da água de um igarapé e de materiais conhecidos do cotidiano para alunos do Ensino Médio noturno, apresentando um baixo custo envolvido no experimento e contribuindo para aplicação da teorica química.

Os discentes tiveram um melhor conhecimento sobre o que são ácidos/bases e foi acrescentado novas característica sobre os mesmos. Os alunos puderam verificar que ácido e base não são somente alimentos e podem ser outros materiais. Em relação a neutralidade, o aprendizado foi mais contundente pois os mesmos tinham muito pouco conhecimento sobre o assunto. Os métodos utilizados de como medir o $\mathrm{pH}$, a fita de tornassol e o indicador do suco do repolho roxo foram absorvidos pelos discente e utilizados nas aulas práticas. O projeto de química trouxe nova visão crítica construtiva sobre como aprender química tanto na prática quanto na teórica

Todos os autores declararam não haver qualquer potencial conflito de interesses referente a este artigo.

\section{REFERÊNCIAS}

ANTUNES, M., ADAMATTI, D. S., PACHECO, M. A. R., GIOVANELA, M. (2009). pH do Solo: 
Determinação com Indicadores Ácido-Base no Ensino Médio. Química Nova na Escola, 31(4), 283-287.

AUSUBEL, D. P. (2003). Aquisição e retenção de conhecimentos: Uma perspectiva cognitiva, Lisboa: Editora Plátano.

BRASIL. Secretaria de Educação Média e Tecnológica. (2202). Parâmetros Curriculares Nacionais: ensino médio/ Ministério da Educação, Secretária de Educação Média e Tecnológica. Brasília: MEC; SEMTEC.

CORTES, M. S.; RAMOS, L. A.; CARVALHEIRO, E. T. G. (2007). Titulações espectrofotométricas de sistemas ácido-base utilizando extrato de flores contendo antocianinas. Química Nova, 30(4), 10141019.

CUNHA, A. P.; SAlgUEIRO, L.; ROQUE, O. R. (2005). Farmacognosia e fitoquímica, Capítulo 22, $1^{\circ}$ edição, Fundação Calouste Gulenkian, 2005.

LOBO, A. M., LOURENÇO, A. M.(2007). Biossíntese de produtos naturais. Lisboa: IST Press.

LOPES, A.S.; SILVA, M.C. e GUILHERME, L.R.G.(1991). Boletim técnico ${ }^{\circ}$ 1: acidez do solo e calagem. 3 ed. São Paulo: ANDA.

LOPES, T. J.; XAVIER, M. F.; NOVY, M. G. (2007). Antocianinas: uma breve revisão das características estruturais e da estabilidade. Revista Brasileira de Agrociência, Pelotas, 13(3), 291-297.

OLIVEIRA, H. R. S. A (2010). Abordagem da Interdisciplinaridade, contextualização e Experimentação nos livros didáticos de Química do Ensino Médio. Monografia (Curso de Licenciatura em Química). Universidade Estadual do Ceará. Fortaleza- CE.
OLIVEIRA, S.R.; GOUVEIA, V. P.; QUADROS, A.L. (2009). Uma reflexão sobre aprendizagem Escolar e o uso de conceito de solubilidade/miscibilidade em situações do cotidiano: concepções dos estudantes. Química nova na escola, 31(1), 23-30.

SANTOS, V. F.; ALVES, B. H. P.; SILVA, L. O. P. (2012). Experimentos lúdicos com materiais alternativos no ensino de química. In: XVI Encontro Nacional de Ensino de Química (XVI ENEQ) e X Encontro de Educação Química da Bahia (X EDUQUI). Salvador, BA, Brasil - 17 a 20 de julho de 2012. Disponível em: <https://portalseer.ufba.br/index.php/ anaiseneq2012/article/download/7761/5669>. Acesso em: 09 de Set. de 2018.

SCHNETZLER, R.P.(1992). Construção do Conhecimento e Ensino de Ciências. Em Aberto, Brasilia, 11(55), 17-22.

SOARES, M. H. F. B., SILVA, M. V. B., CAVAlHEIRO, E. T. G. (2001). Aplicação de corantes naturais no ensino médio. Eclética Química, 26(1), 98-103.

TERCI, D. B. L., ROSSI, A. V. Indicadores naturais de pH: usar papel ou solução?. Química Nova, 25(4), 684-688, 2012.

UCHÔA V. T.; CARVALHO FILHO, R.S.M.; LIMA, A.M.M.; ASSIS, E. J. B. Utilização de Plantas Ornamentais como novos indicadores naturais ÁcidoBase no Ensino de Química. Holos. 32(1), 152-165, 2016.

YAMAGUCHI, K. K. L.; NUNES, A. E. C.; Dificuldade em química e uso de atividades experimentais sob a perspectiva de docentes e alunos 
do ensino médio no interior do Amazonas (Coari).

Scientia Naturalis, 1(2), 172-182, 2019, 